\title{
1. Regulation: theory and practice
}

This work is part of a long academic tradition of the study of economic regulation and its effects in the economic efficiency of an industry. This chapter will provide some background on the theoretical issues regarding economic regulation and the practical applications of some concepts. This chapter does not intend, however, to be a comprehensive study on the theory of economic regulation. It should be regarded as an overview of concepts, with a focus on the aspects that are most relevant to the transportation sector in general and the aviation industry in particular. The interested reader will find a much more complete analysis in other works, including the ones that are referenced and listed at the end of this book.

The chapter starts with a quick outline on the rationale for economic regulation. The next section presents the work of two major schools of thought in the current regulatory paradigms: Alfred Kahn and the authors of the Chicago School. Since theory cannot work without practical means of application, in section 1.3 a few regulation mechanisms are discussed. Finally, some conclusions are drawn.

\subsection{THE RATIONALE FOR ECONOMIC REGULATION}

Economic regulation has been seen as the 'government's necessary and beneficial response to market failure' (Coppin and High 1999, p. 8) to 'induce firms ... to act in a way that is compatible with social goals' (Train 1991, p. xi). Translated into simpler words, economic regulation is used to maximise social welfare. Governments have used this thinking to intervene when the presence of a market along with Adam Smith's 'invisible hand' is not enough of a guarantee of socially desirable outcomes and the public interest is not protected. ${ }^{1}$

While a simple concept in principle, the practical applications of economic regulation have followed the predominant economic concepts, the political thinking that backed them up, and the economic conditions of each period. These differences in interpretation resulted in economic regulation being applied with significant differences since at least the 
nineteenth century. ${ }^{2}$ Focusing on more modern times, economic regulation ranged from a strong presence in a wide range of industries in the post-Great Depression years, to the deregulation efforts of the mid-to-late twentieth century.

\subsection{THE CHANGES IN REGULATORY PARADIGM}

\subsubsection{Alfred E. Kahn}

Alfred Edward Kahn was an American economist who played a pivotal role in the development of regulatory thinking in the 1960s and 1970s, both in academia and in public service, as the chairman of the New York Public Service Commission and the Civil Aeronautics Board (CAB).

To the theoretical treatment of economic regulation, Kahn's contributions are perhaps best represented in his two-volume seminal work The Economics of Regulation: Principles and Institutions (1970, 1971), where issues relating to the economic and institutional implementation of regulation were explored in great detail. The first volume underscores the need for and the implementation of economic regulation. This volume is a presentation of the main concerns regarding the regulatory frameworks of the time and is also a discussion of the economic principles that could be used to improve them.

Kahn's criticism of the regulatory procedures fell into three main categories: quality of service, rate levels and the rate structure. The lack of market competition under regulation, especially for those, such as public utilities, that enjoyed a market monopoly, did not provide many incentives for the firms to pay attention to quality of service. Indeed, incentives and how the regulatory structure of the time did not create them permeates the two volumes of the book. Since regulators were concerned with rate levels, quality of service was often seen as being the responsibility of the firm. As those firms had no incentives to improve quality of service, it remained subpar. ${ }^{3}$ On the other hand, the regulatory framework did offer some indirect incentives in terms of quality of service because the prevailing rate-of-return regulation that was put in place offered an incentive for overinvestments in capital. As such, firms could invest on improving service, knowing that regulators would allow the firms to reap benefits from that investment. Additionally, the public was critical about the failures of regulated firms in providing adequate service. Firms thus had an incentive to pre-emptively act in order to avoid intervention of the regulators in response to those criticisms. 
Regarding rate levels and how they should be established, Kahn points to several issues. First, there is the issue of asymmetry of information. Since companies know much more about their own business than the regulators, there are incentives for the firms to only disclose information that would work best for their own benefit, for example, to exaggerate their costs in order for rate increases to be allowed. In turn, regulators have to spend great amounts of resources in order to try to close that information gap. For the regulators to have access to the same level of information, they would have to run the company themselves, or almost do so. Eventually, many governments did so with government-owned corporations and other public agencies.

In addition, traditional rates-of-return regulation was supposed to allow firms to charge prices and have a rate of return on capital that would allow them to operate successfully, attract capital for new investments and reward investors with an appropriate rate of return on their investment. Nevertheless, as regulators were not privy to all the firms' information, it would not have been known if the rate chosen would create incentives for the companies to reduce costs. Moreover, the goods or services being regulated did not have a competitive market most of the time ${ }^{4}$ thus creating another level of blindness for the rate-setting regulators.

Finally, the issue of rate structures - what rates can be charged to a specific group of users - was mainly a problem in the transportation industries; public utilities had more discretion in setting their own rate structure. At the time, trucking companies, canals, railroads and airlines where all subject to economic regulation in the US and other countries. For these transportation firms, regulators, as well as the courts, intervened to avoid unfair discrimination among customers, firms, modes, etc. Those decisions were a mixture of economic principles along with political and social considerations. From an economic perspective, the decisions did not necessarily take efficiency as their main concern.

For Kahn, the solution for this problem is the use of marginal cost pricing principles. Marginal cost can be defined as 'the cost of producing one more unit [or] the cost that would be saved by producing one less unit' (vol. I, p. 65). Since production is limited, there is an opportunity cost associated with consuming a good. Thus, it can be argued that the most welfare-maximising way for the society to allocate the resources necessary to produce that good, would be to charge the price that maximises the utility of the consumer: the marginal cost. This of course is a purely economic argument and does not take into consideration non-economic considerations, such as equality or social issues, or national security for example, but as Kahn puts it 'this, too, is an ethical 
judgment, not an economic one' (ibid. p. 68) and the issue was being discussed by Kahn from an economic perspective.

Setting marginal pricing has its own set of issues. It is not only impractical but also expensive for firms to establish the true marginal cost of each additional unit they produce. Also, ever-changing prices would confuse consumers and increase their costs to keep informed about them. As a result, compromises had to be made between charging true marginal costs and keeping pricing feasible. ${ }^{5}$

The second volume of Kahn's seminal work has a more practical approach, dealing with institutional and governance issues related to the implementation of economic regulation. Without institutional frameworks to implement economic theories, these can become irrelevant. For Kahn, two features characterise economic regulation: protectionism and conservatism. Even though regulatory schemes are "vigorous, imaginative, and enthusiastic' (vol. II, p. 11) when they are put in place, after a certain amount of time, bureaucracies become engrained. Firms learn how to deal with their regulators and have regulation working for their best interest (protectionism), essentially capturing the regulator. Any changes to the status quo are considered to be potentially risky and destabilising (conservatism).

As mentioned before, the lack of incentives for regulated firms to improve their performance is an issue of concern when setting a regulatory structure. Kahn considers that performance can be assessed in five different ways: efficiency, that is, cost; the relationship between prices and cost (marginal pricing); improved efficiency over time and passing of those savings to consumers; quality of service; quality of service improvements over time. The question then arises on how to measure the relevant variables in each one of these categories. For that purpose benchmarking can provide helpful tools.

For companies to keep improving in the goods or services they offer by providing ever cheaper, ever better goods or services - they need to have incentives. For a company operating in a competitive market, the biggest incentive in existence is the maximisation of profit; to achieve profits firms have to offer goods and services that customers want. For a company operating under strong economic regulation, there is also that incentive to maximise profits, however, the regulatory scheme put in place can distort that goal by imposing limits on what levels of profits are deemed acceptable or just.

Regulated firms also have an additional incentive to keep costs under control and provide quality service: being under public scrutiny. Managers have an incentive to provide good service and to avoid asking for rate increases; otherwise, their image with the public could be hurt. Also, 
elastic markets provide incentives; if the prices are set too high, consumers will not buy their products, so the more elastic the market is, the more incentives there are for the products to be sold at a purely competitive level. This is not the case, however, of industries such as utilities that provide essential services; water or electricity markets, for example, are only elastic up to a certain extent. In many countries with more interventionist governments, there is the additional incentive of a possible government takeover: if the regulator believes that the firm is producing at higher costs than they should, the government can either take the operation into their own hands, or give the monopoly to another company.

In summary, the need of regulation or not comes from a simple question: 'does it do more good than harm?' (Kahn 1970, vol. II, p. 111). The answer is (at least) twofold. When a company can exercise a great deal of monopoly power, effective regulation can help to protect consumers and fight inefficiencies and decreases in the quality of service. In this scenario, the benefits might outweigh the costs. On the other hand, in markets where regulation imposes restrictions on competition that otherwise would exist, regulation may do more harm than good. This happens because regulation is much less effective than competition in promoting innovation and decreasing costs. As Kahn stated: 'If I knew what was the most efficient and rational arrangement, I'd continue to regulate' (cited by Button 2015).

Kahn's contributions did not come to existence in a bubble, but rather at a moment of history when economists began to see in a different light the regulatory structure that had been put in place following the Great Depression and World War II. This was the case, for example, in the telecommunications industry, which had been considered as a natural monopoly for decades, mainly due to its high fixed costs. ${ }^{6}$ It was provided either by a public firm (the case in most of the world) or a private regulated corporation (the case of AT\&T in the US), however, these companies were believed to be quite inefficient, usually overinvesting or investing poorly, leading to higher prices than could be expected. They also had distorted price structures, with costs being allocated arbitrarily between the different users, and cross-subsidies not being delivered in the most socially desirable manner (that is, subsidising those who need it the most).

The same economic thinking, but applied to airlines, was becoming prevalent when Kahn became the chairman of the CAB in 1977. This was a job he had for only 18 months, and which he did not want in the first place, as he instead wanted to be the chairman of the Federal Communications Commission. Several publications and studies claimed that the 
regulatory scheme in place created a de facto cartel in the US airline industry, ${ }^{7}$ resulting in competition not on prices (because that was not allowed), but on service (better food and drinks, in-flight entertainment, etc.), and over-scheduling of flights, and consequently, low load factors. ${ }^{8}$ In fact, although Kahn was at the helm when deregulation took place, some levels of deregulation had already been put in place by his predecessor John Robson, including the creation of 'peanut' fares at discounted prices as well as the deregulation of cargo services in the year before passenger services were deregulated.

Both telecommunications and airlines went through extensive changes in economic regulation, and in fact the same happened to many other industries in the Western world in the 25 years that followed the publication of Kahn's works, either by means of complete deregulation, ${ }^{9}$ or by rearrangements of the economic regulation schemes previously in place. Winston summarises Kahn's contributions by claiming that Kahn 'became known as the father of one of the largest Pareto improvements during the postwar period - economic deregulation' (2012, p. 391).

\subsubsection{The Chicago School and the Capture Theory}

In the perspective of the Chicago School, epitomised by authors such as George Stigler and Harold Demsetz, economic regulation ends up not being used to protect and benefit the public/consumer, but to protect the industry being regulated; this is considered regulatory capture. This idea was not new, and can be traced back at least as far as Karl Marx in the nineteenth century.

According to Stigler (1971), industry profited from the status quo (at the expense of consumers) by a process of rent seeking aimed at increasing their profits, with regulation being designed and operated for the benefit of industry. This was conducted, Stigler argues, via four types of policies: direct subsidies, control over entry of new rivals, control over industries that produce substitutes or complements and price-fixing. ${ }^{10}$

A subsidy is the most obvious form of benefit that a company can receive from a government. Nonetheless, Stigler argues that this benefit is not normally the one that an industry is most eager to seek. If there are no barriers to enter the market, the pool of money available will have to be given to a growing number of companies. That growing number of companies will then diminish the amount each company receives. This leads to the second type of policy: control over entry of new rivals. This creates de facto oligopolies where entering is either impossible (because the regulators simply do not allow it), or where the barriers are so numerous that the costs of entry are prohibitively expensive. The third 
policy, control over industries that produce substitutes or complements, is the case where the state protects an industry either by hindering the prospects of industries that produce substitutes or by helping industries that produce complements. The example used in Stigler's paper is of butter producers who wish to suppress margarine (the substitute) and encourage the production of bread (the complement). Finally, price-fixing is the case where the prices are administratively set, instead of being set by the market. Price-fixing is desirable by the firms because it can be used to achieve excessive rates of return.

Stigler argues that this state of affairs, in which an industry receives benefits that are smaller than the damages incurred by the rest of the community, are a direct result of the political process in democracies. The state has, as Stigler puts it, the 'power to coerce' (1971, p. 4), which neither the market or any of the state citizens have. Also, the decisions of state are infrequent, universal and simultaneous; that is, if the state decides to regulate an industry, that decision affects all the users and all the non-users of the services of that industry, present and future. Since it would be impractical for the citizens to vote on every single matter, they have to vote on representatives that will vote on those matters for them. Because those representatives have a wide range of voting preferences, voters need to choose a representative by giving their preference to a number of topics on which they agree, even if they disagree with a number of others. Also, there is a high cost (and not many incentives) to acquire knowledge on every single topic on which a representative will potentially vote, so even the most informed voter will not have the knowledge to vote consciously on many matters. These intrinsic characteristics create political processes that are 'gross or filtered or noisy', which 'disregard the lesser preferences of majorities and minorities' (ibid. p. 12), creating a system where industries seeking regulation can focus their attention on candidates/political parties that will help them achieve their goals. The benefits thus go to both the industries and the candidates at the expense of the rest of the community.

Coppin and High (1999) argue that the regulatory capture theory, in which regulated firms gain control over the process by which they are regulated, does not always hold true, with numerous examples existing in which regulation is not captured by the regulated industry. An example of this is the Hepburn Act of 1906 that gave the Interstate Commerce Commission (ICC) the power to set maximum railroad rates, and was opposed by almost all railroads. On the other hand, Kolko (1963) suggested that during the 1870 s and 1880 s railroads had a pivotal role in lobbying for the creation of the ICC because it would isolate railroads 
from state regulations that they would be less capable of controlling, and stabilise price levels in competing markets.

Laffont and Tirole (1993) add to Coppin and High's argument by discussing the methodological limitations of Stigler's capture theory. Adding to this point, Gómez-Ibáñez (2003) argues that the Chicago School authors view regulatory agencies as being controlled by one political master (the politician who had the most votes), while in reality, regulatory agencies can be influenced by a great number of elected and unelected officials (along with other stakeholders and interest groups) at different levels of government, making it harder for one group of interests to influence decisions decisively.

Another important author of the Chicago School was Harold Demsetz, who in a 1968 paper attempted to deconstruct many of the arguments that at the time were used to justify regulating public utilities and natural monopolies. One of the main arguments of Demsetz's paper is that although there might be such economies of scale that the production of a given good is undertaken by only one producer (that is, a natural monopoly), it does not automatically mean that monopoly prices will necessarily ensue. If a bidding process (or an auction) is implemented, the existence of many bidders that are aware that unless they have the lowest price they will not win the auction, the price of the good or service will not be a monopoly price.

Auctioning monopolies has become increasingly common in the decades that followed the publication of Demsetz's paper, which is a sign that the author's general idea has proven its relevance over the years. Nevertheless, the author's assessment of these ideas can be deemed as lacking some impartiality. For example, the example chosen as a natural monopoly, production of license plates for automobiles, does not in any way involve the complexity of providing services like electricity or air traffic control. Not to mention the fact that although license plates are manufactured as a monopoly in many US states, it is hard to argue that they have any characteristics that make them a natural monopoly.

Also, although issues such as right of way and utilities' distribution systems are discussed, there are almost no mentions of transactions costs and judicial disputes that might arise if new entrants in a market decided to build new overlapping distribution systems in totally unregulated markets. Other concerns such as sunk costs or the duration of franchises are not discussed or even mentioned. ${ }^{11}$ While making license plates might not entail investing significant amounts of capital that are not recoverable and a new provider can be chosen every year, that is probably not the case of services such as sewage treatment or natural gas distribution. 


\subsection{DIFFERENT FORMS OF REGULATION}

\subsubsection{Rate-of-return}

Rate-of-return, or cost-of-service, regulation was the most-used regulatory scheme for private monopolies for many decades. With this method, the regulator defines a rate-of-return on the firm's investment in capital that is considered to be fair and does not result in excessive levels of profits. Besides that limitation, companies can choose their levels of inputs, outputs or the prices of their products.

The rate-of-return on capital is defined by Equation 1.1:

$$
\text { Rate }- \text { of }- \text { return on capital }=\frac{P \cdot Q-w \cdot L}{K}
$$

With P.Q being price and outputs (that is, revenues), w.L being wages and other non-capital inputs (that is, costs for non-capital inputs), and $\mathrm{K}$ being the level of capital investment.

In a rate-of-return regulatory scheme, this rate defined in Equation 1.1 has to be lower than the fair rate $f$, defined in:

$$
f \geq \frac{P \cdot Q-w \cdot L}{K}
$$

From Equation 1.2, $f$ has to be higher than the cost of capital: if it is below the cost of capital, the company will make more profit by closing operations and selling its capital - assuming the regulators allow it. Otherwise it will reduce its capital as much as possible, possibly resulting in less output and higher prices. If $f$ is the same as the cost of capital, there is no profit maximising solution, and the company will have no incentive to act in the way the regulators intended; no matter what level of inputs or outputs, or what input mix it had, it would always have the same profit.

Besides the problem of setting an appropriate fair rate, this scheme has two other disadvantages: it promotes X-inefficiency (Leibenstein 1966) and the Averch-Johnson effect (Averch and Johnson 1962). $\mathrm{X}$-inefficiency occurs when companies do not minimise the costs needed to produce a given output. Under rate-of-return regulation, there are no incentives for the companies to do so, since when a firm's production costs increase they might be able to request a price increase in order to maintain their rate-of-return. However, the existence of regulatory lag the time it takes before a requested new price is approved - helps to 
countervail this problem. This is because if a firm increases its costs and requests a price increase, which might not even be approved, in the time it takes between making the request and being able to charge the new price, the firm will be earning a rate-of-return that is less than expected; similarly, if the firm manages to reduce costs, until the regulator approves a price decrease it will be earning a rate-of-return that is higher than expected (Waldman and Jensen 2012).

In theory, rate-of-return regulation theory has the advantage of guaranteeing that companies would be able to recover their costs and that the absence of risk would attract capital at low prices. However, it has been found that under these regulatory schemes, firms have incentives to use more capital than needed and to use inefficiently high capital/labour ratios; the Averch-Johnson effect. ${ }^{12}$ Outputs could thus be produced more cheaply if the firm used more labour and less capital. These two flaws in the structure of this type of regulation create an incentive system based on the amount of capital that the firm invests, and does not lead the firm to operate efficiently and produce at minimum cost, once again leading to $\mathrm{X}$-inefficiency.

\subsubsection{Price Capping}

A more recent form of regulation, developed in the 1980s in the UK in the context of the telecommunications industry, is price-cap regulation. This method of regulation has replaced rate-of-return regulation in many markets in order to try to overcome its shortcomings. Under this scheme the firm is incentivised to become increasingly efficient and lower the prices (in real terms) of its services continuously. This is achieved by setting a price cap under the formula $C P I-X$, in which $C P I$ is the inflation rate (consumer price index) and $X$ is the expected efficiency gains. If the savings fall above the predicted rate (that is, if the firm can produce at a price lower than the regulator demands), the extra profits can be passed to the shareholders, which creates an incentive to achieve greater levels of efficiency. However, sometimes regulators impose some restrictions and if the firms become too efficient - that is, if they are deemed to have more profit than is acceptable - the savings might have to be passed, at least partially, to the consumers. This has happened, for example, in 1995 in the United Kingdom. Due to political and consumer pressure based on the belief that the companies had excessive profits), the prices caps that the regional electricity companies were operating under were revised and lowered, ahead of the planned review process.

One of the main problems with this form of regulation is the determination of $X$ : it should be a proxy for a competitive market and be 
based on the firm's past performance as well on the performance of other firms that operate in the same industry - a proxy for its determination could be the improvements of total factor productivity (TFP) $)^{13}$ - but, as the efficiency increases, $X$ approaches a normal profit margin and price capping essentially becomes rate-of-return regulation.

Other problems can also be identified in this method of regulation: quality concerns, regulatory capture and regulatory taking. Quality concerns appear when the company reduces the quality of services in order to be able to supply the service at a price equal (or below) the price cap. This price cap acts as an incentive to save whenever possible to maximise its profits; that is, while rate-of-return regulation provides incentives for overinvesting, price-capping regulation provides incentives for underinvesting. This issue with quality is exacerbated by the fact that contracts and the value of $X$ are revised periodically. Because of this, firms have an incentive to focus on matters that lead to short-term gains, disregarding long-term improvements.

Regulatory capture à la Stigler, and regulatory taking are both related to the issue of the power of discretion that regulators have: when there is regulatory capture, the regulator is deemed to be too soft and allows companies to have inflated rents; on the other hand, when there is regulatory taking, the regulator is too harsh and reduces compensation to the company to very low levels, not giving enough compensation for its investments and efficiency improvements. Initial hopes that price caps would lead to fewer issues with regulatory capture - mainly because it was believed that firms would have greater incentives to disclose their true costs so that a fairer $X$ could be set - have not materialised, and determining $X$ has become as much of an issue as the setting of rate-of-return had been. Firms still withhold information to gain advantages, thus putting additional burdens on regulators and increasing the chances of being able to capture the process for the firm's gain.

\subsubsection{Auctioning Monopolies}

As discussed in Section 1.2.2, auctioning monopolies is a method that, paradoxically, should allow for the presence of a monopoly without the corresponding monopoly price. In recent years, it has become widely used, for example, when attributing franchises for the operation of mass transit services such as rail and bus lines or transit networks.

With this method a regulator decides that a service must be provided. Due to the nature of the service, it must be provided as a monopoly. Since by definition a monopoly does not allow competition, the regulator creates an auction, where the different companies interested in providing 
the service can bid for the right to do so. Auction systems vary; ${ }^{14}$ they can have simultaneously or sequential bidding; bids can be public or secret, etc. Regardless of the system implemented, the goal should be similar: create competition in order to incentivise companies to bid the lowest price possible for the product, that is, the price for which the company has zero economic profits. ${ }^{15}$

For this model of regulation by auction to result in lowest possible per-unit cost and not a monopoly price, Demsetz (1968) presents two major requirements: the inputs required to enter production have to be available at market prices to many potential bidders and the cost of collusion between bidding rivals has to be 'prohibitively high'. These two requirements to avoid monopoly prices are the same as in any market, regardless of the existence of economies of scale that lead to the emergence of natural monopolies or not.

One of the major problems with this kind of regulation is that the lowest, optimal, price is only true at the moment of bidding. Also, it can change during the period for which the company has the monopoly: if production prices increase during the period, and the company is not allowed to raise the price it charges its consumers, it can become insolvent; if production prices decline and prices stay the same, consumers are, in essence, being overcharged. Asymmetry of information plays a significant role here, since companies do not have an incentive to share with the regulators that they were able to reduce costs and are charging consumers the same, and when production costs rise they are more likely to inform the regulator immediately and request changes in prices if allowed by the contract.

Contracts can have clauses to deal with this situation, but then we can be in the presence of de facto rate-of-return and price cap, depending on how the contracts deal with changes in production costs. Additionally, it might not be ideal to allow for the renegotiation of rates when production costs decline, as declining production costs provide an incentive for the monopolist company to become more efficient and keep the additional profits.

A possible solution to this problem would be to run a new auction, allowing competitors to bid for the new lowest prices, but this solution would be impractical because prices can change several times in a short period of time. It can also be complicated from a legal standpoint because of the existence of existing contracts. A more feasible solution is to sign contracts that are neither too short (not giving firms enough time to develop their market and have incentives to reap the benefits of improved efficiency) nor too long (not allowing consumers to also gain from the improved efficiency of the service provider). After each contract 
ends, a new action is set up and, in theory, bidders would present a new price based on the gains in efficiency that the industry has achieved since the last auction. A new contract would then be signed with the company that now offers the lowest prices. Information asymmetry plays a role here, with incumbents being privy to more detailed information about the production system, having an advantage when new auctions are set up.

\subsubsection{Ramsey Pricing}

Created by Frank Ramsey in 1927 in the context of optimal taxation, Ramsey pricing became an important contribution to regulation theory, namely regarding the issue of pricing of multi-product monopolies. This is the case, for example, of a firm that either sells two different goods (say, a utility company that sells both natural gas and electricity) or the same good with different characteristics (for example, a utility company that sells electricity at different prices according to the time of day off-peak, peak-hour, peak-of-peak, etc.).

When companies that have the goal of achieving zero economic profits, as is the case of regulated natural monopolies, sell more than one product, achieving zero economic profits is a problem with multiple solutions. Ramsey pricing deals with this issue by trying to find the combination of prices that maximises the total consumer surplus while allowing the provider to break even. At the Ramsey price equilibrium, the amount by which price exceeds marginal cost, expressed as a percentage of price, is bigger for products with less elastic demand (the inverse elasticity rule). ${ }^{16}$

Having the result of maximising total consumer surplus while allowing the provider to break even, Ramsey pricing does not take into consideration the distribution of that surplus. This can create a problem of social welfare and inequity. When one provider, such as an ANSP, serves very distinct consumers - say general aviation and commercial aviation - this might lead to a situation where the strict application of Ramsey pricing leads to one group of consumers subsidising other groups, and equity issues can arise as a result.

In fact, this is a direct consequence of the creation mechanism of Ramsey prices, which raises the costs of goods with lower elasticity above marginal costs, which means that people who buy those goods are likely to keep buying them even if they are more expensive. In some types of services, for example mass transit, the people who are more inelastic to its price are lower income people (because they do not have any other mobility options - this might also be the case of the younger and older cohorts of the population), thus raising the price to those 
inelastic consumers is in fact subsidising the ticket of more elastic, probably better-off, consumers who could choose to use the automobile for those trips.

Ultimately, the regulator has the possibility to act in order to achieve a more equitable redistribution, but that can also affect the demand on the products, thus creating non-Ramsey prices.

\subsection{CONCLUSION}

Economic regulation has evolved tremendously in the last 100 years. The beginning of the twentieth century brought about the intervention of governments in matters such as the curbing of excessive monopoly power. Even greater government intervention followed the Great Depression and World War II. Government ownership and strict rate-of-return regulation became the norm in many industries, most notably in natural monopolies such as utilities and transportation infrastructure and services.

In the 1960s, academia started to challenge many of the assumptions that had led to this regulatory landscape, and the following decades brought many deregulatory efforts. Still, many natural monopolies did not stop being natural monopolies, and for those, more efficient and cleverer forms of regulation have been envisioned. While rate-of-return regulation used to be the predominant form of regulating natural monopolies, new models such as price cap and auctioning franchises, have brought new ways of putting economic regulation theory intro practice. 